\title{
What Can We Learn About Economics from Sport during Covid-19?
}

by Alex Bryson, Peter Dolton, J. James Reade, Dominik Schreyer and Carl Singleton

Discussion Paper No. 2021-01

Department of Economics University of Reading Whiteknights

Reading

RG6 6AA

United Kingdom

www.reading.ac.uk 


\title{
What Can We Learn About Economics from Sport during Covid-19?
}

\author{
Carl Singleton, ${ }^{\text {a, }}$ Alex Bryson, ${ }^{\mathrm{b}, \mathrm{c}}$ Peter Dolton, ${ }^{\mathrm{c}, \mathrm{d}}$ J. James Reade, ${ }^{\mathrm{a}}$ Dominik Schreyer, ${ }^{\mathrm{e}}$ \\ ${ }^{\text {a }}$ Department of Economics, University of Reading \\ ${ }^{\mathrm{b}}$ Social Research Institute, University College London \\ ${ }^{\mathrm{c}}$ National Institute of Economic and Social Research \\ ${ }^{\mathrm{d}}$ Department of Economics, University of Sussex \\ ${ }^{\mathrm{e}}$ Center for Sports and Management (CSM), WHU - Otto Beisheim School of Management
}

January 2021

\begin{abstract}
The economics of sport and how sport provides insights into economics have experienced exogenous shocks from Covid-19, facilitating many natural experiments. These have provided partial answers to questions of: how airborne viruses may spread in crowds; how crowds respond to the risk and information about infection; how the absence of crowds may affect social pressure and arbitration decisions; and how quickly betting markets respond to new information. We review this evidence and advise how sports economics research could continue to be most valuable to policymakers.
\end{abstract}

Keywords: Sports Economics, Coronavirus, Natural Experiments, Referee Bias, Social Pressure, Prediction Markets

JEL Codes: D91, L83, Z20

*c.a.singleton@reading.ac.uk (corresponding author) \& j.j.reade@reading.ac.uk, Department of Economics, University of Reading, Whiteknights Campus, RG6 6UA, UK. a.bryson@ucl.ac.uk, UCL's Social Research Institute, UCL, 20 Bedford Way, London, WC1H 0AL. p.dolton@sussex.ac.uk, Department of Economics, University of Sussex, Brighton, BN1 9SL. dominik.schreyer@whu.edu, Center for Sports and Management (CSM), WHU - Otto Beisheim School of Management, Erkrather Str. 224a, 40233 Düsseldorf, Germany. 


\section{Introduction}

Sport can offer rare moments of clarity to social scientists within an otherwise complex real world. The competitive environments in sport provide laboratories to study human behaviour, to test theories, and to observe the effects of policy. In this paper, we take an editorial cue from a recent special issue of the Journal of Behavioral and Experimental Economics: "Ask not what economics can do for sports - Ask what sports can do for economics" (Bar-Eli et al., 2020). In this spirit, economists have been studying the impacts of Covid-19 on sports, and vice versa, addressing research questions that have important implications far beyond the fields of play. We briefly summarise these studies and give our views on the questions that sports economists should try to answer next.

\section{Mass events and the spread of an airborne virus}

Before Covid-19, there was surprisingly little evidence on the causal effects that sports events could have on the spread of an airborne virus. A notable exception used the locations of the National Football League (NFL) Super Bowl, and the home cities of the teams making it there, to estimate the impacts of this annual mass winter gathering of sports fans on seasonal influenza mortality (Stoecker et al., 2016). Using a differences-in-differences design, the study found an $18 \%$ increase in influenza mortality in the over $65 \mathrm{~s}$ in the cities represented in North American sport's annual showpiece, between 1974 and 2009, compared with the cities that did not make it to the Bowl. There was no increase in mortality in the cities hosting the Bowl, suggesting that the increased gatherings of people in social settings back home, away from the stadium, could be part of the mechanism spreading the virus.

Also studying seasonal influenza in North America, a more recent study exploited the movement or creation of major sports franchises between 1962 and 2016, as well as the periods when sports stopped, e.g., due to player strikes (Cardazzi et al., 2020). The study found significant increases in influenza mortality of 4-24\%, depending on the sport, when franchises arrived in cities, compared with before they arrived and other cities without franchises. The impact of league stoppages was mixed, with effects on mortality of the 1982 NFL and 2011 National Basketball Association (NBA) stoppages, but not the 2004 National Hockey League (NHL) stoppage. The authors also found a parallel with Stoecker et al. (2016), as there was a significant increase in all-cause mortality in over $65 \mathrm{~s}$ when a new NFL sports franchise arrived 
in a city. However, neither study could pin this down to fans attending stadiums, as opposed to the general gathering of people to watch sports events, e.g., in their homes or bars.

The first study of whether major sports events can cause the spread of Covid-19 focused on North America (Ahammer et al., 2020). By exploiting the variation in the scheduling of NBA and NHL games in a twelve-day period in early March 2020, the study was able to estimate the effects of these large indoor gatherings on the subsequent spread and mortality of Covid-19. The authors concluded that each of these mass gatherings, on average, increased the cumulative number of deaths directly from Covid-19 by $9 \%$ up to the end of April 2020, in the areas around where the events took place.

Using a similar empirical design, another study has looked at the impact of English football matches taking place with crowds as the Covid-19 pandemic took hold (Olczak et al., 2020). Even though these events took place outdoors, compared to the indoor events studied in North America, the authors also concluded that attendance at matches resulted in local increases in the spread of Covid-19. Each match added six Covid-19 cases, two Covid-19 deaths, and three excess deaths per 100,000 local people (See Figure 1).

This small literature, on the potential of sports events to spread the virus, suggests that extreme caution needs to be applied by policymakers on when and how to reopen sports stadiums to spectators. This is underlined by another literature that suggests social distancing will not happen naturally from large numbers of sports fans voluntarily staying away from stadiums.

\section{Stadium attendance demand and risk taking}

The demand for attending sports events during the pandemic may tell us something about how populations respond to a public health emergency, especially one which requires social distancing, under different policy regimes. It may provide more general evidence on how individuals respond to negative risk and uncertainty.

Since most governments shut down professional sports quickly in Spring 2020 and subsequently restricted the numbers of fans allowed to return, with massive unmet demand, opportunities to gain novel insights from stadium attendances have so far been limited. Reade and Singleton (2020a) used the predetermined scheduling of football matches in early 2020 in Europe's major leagues, to test whether public news about domestic or global virus cases and 
deaths affected stadium attendances. The study found no negative demand association between the global news about the progress of the outbreak and stadium attendance demand. However, in Italy, England and Germany, the previous day's newly confirmed domestic cases or deaths appear to have negatively affected attendances, though this was not the case in France or Spain - for France, one explanation of this difference could have been the competitive nature of the 2019/20 season just before it was abandoned.

In the only European professional football league to not temporarily shut down due to Covid-19, Belarussian stadium attendance demand declined significantly in the initial period of maximum uncertainty about the virus and its lethality (Reade et al., 2020a). Demand in this league then slowly recovered, despite the ongoing inherent risk to individuals from going to a match. This would be consistent with other research from North America showing that some fans who were surveyed and subject to a discrete choice experiment, in August-September 2020, were largely still willing to accept Covid-19 risks to attend stadiums, even knowing the risks, though with some reduced demand (Humphreys et al., 2020). For example, the willingness to pay (WTP) of NFL and NHL fans in the experiment increased by about $50 \%$ when told there would be a mask requirement at a stadium limited to $25 \%$ capacity, as opposed to no mask requirement and the same capacity limit. The WTP increased by as much as $130 \%$ for fans posed with the same scenario in Major League Baseball and the NBA.

\section{Behaviour, bias and social pressure: sport behind closed doors}

The social environment has the potential to affect individuals' decisions and choices (e.g., Becker and Murphy, 2000). This has been demonstrated for the referees of sporting contests. There is widespread evidence that they are affected by social pressure (see the survey by Dohmen and Sauermann, 2016). The substantial advantage that football teams normally have when playing at home, mostly in front of their own supporters, is partly attributable to the impact the crowd has on refereeing decisions.

The Covid-19 pandemic has induced worldwide natural experiments on the effects of crowds. We exploited one of these experiments that took place over several countries in almost identical settings: professional football matches played behind closed doors within the 2019/20 league seasons (Bryson et al., 2021). 
Figure 2 shows a decline in home advantage in professional football competitions worldwide, which began some time ago, but which became more pronounced since Covid-19, when most matches were played without crowds. Figure 3 focuses on the 2019/20 football seasons for the 17 countries and 23 leagues in our study: it indicates a lot of heterogeneity in whether home advantage increased or decreased after Covid-19 when measured in terms of goal difference, but a clear diminution in the home advantage in referee card-giving for player offences.

Before Covid-19, professional football behind closed doors, without a crowd, was rare, and was usually a punishment inflicted on clubs for their fans' poor behaviour. Studies of these one-off events have found that the referees tended to favour the home team relatively less when handing out punishments for foul play, but this was not enough to significantly affect the final match outcomes (Pettersson-Lidbom and Priks, 2010; Reade et al., 2020b).

Addressing team and referee heterogeneity, we found average effects of playing behind closed doors in the 2019/20 season that were consistent with the aforementioned pre-Covid-19 estimates, which had relied on much smaller samples of matches: no significant general impacts on match outcomes or score lines, but fewer yellow cards awarded to away teams (Bryson et al., 2021). There have been several other studies of these patterns since Covid-19, either using sub-samples of our data (e.g., Endrich and Gesche, 2020) or alternative empirical approaches (e.g., Benz and Lopez, 2020; Scoppa, 2021), finding similar results (see the summary in Reade et al., 2020b).

Football referees can be unfairly biased against away teams by the presence of a crowd and the social pressure it creates. This has implications for the judging and citing of any competitive event or outcome, when it is anticipated that the audience could be partisan, for example, in the Olympics, reality TV contests or even jury trials. More generally, any contest with adversaries and a crowd needs to be set up in such a way as to minimise the potential biases arising from the partiality of adjudicators who may be influenced by the crowd.

\section{Betting markets \& information efficiency}

To gain insights on the informational efficiency of financial markets and the behavioural biases of the participants, a large literature has studied prediction or betting markets, typically those relating to sports events (e.g., Levitt, 2004; Snowberg and Wolfers, 2010; Croxson and Reade, 2014). Unlike conventional financial markets, sports betting provides 'real world laboratories' 
in which to test the Efficient Market Hypothesis and study the departures from it, as participants are generally regarded as being well-informed, motivated, experienced and, most importantly, breaking news is usually reported cleanly, in a way that is easy for the participants to share and process. It is also an advantage that the assets (bets) in these markets have defined end points upon which their values become certain, which is typically not the case when evaluating financial securities pricing (Thaler and Ziemba, 1988).

When football returned after its brief shutdown in Spring 2020, the change in home advantage in professional sports represented new information for markets. Three studies have looked at the accuracy and speed by which this was reflected in prices (Deutscher et al., 2020; Fischer and Haucap, 2020; Meier et al., 2020). The first two of these studies found that prices were slow to adapt for the early German "Ghost Games", indicating a lack of market efficiency, and thus providing profitable opportunities for bettors. The latter study also showed this pattern in the other European leagues when they returned, with it taking up to 30 days since the first German games for the inefficiencies to vanish. Given that the Covid-19 literature on football home advantage without fans suggests mixed evidence across the world's leagues, but a significant reduction in Germany, it could be that bettors and bookmakers just viewed what was happening in the Bundesliga as a plausible outlier. Nonetheless, these three studies add to some previous literature demonstrating how betting markets can offer abnormal returns for participants who react quickly to major structural changes in the nature of the events, or temporal inefficiencies - in this case, markets were slow to adjust away from their long-held beliefs about the scale of home advantage in football. It is important to caveat that these inferences are only relevant for other financial markets in so far as the participants' behaviour is comparable to sports bettors.

\section{What should economists look at next in sports?}

Policy makers need more evidence on if, when and how it is safe to open sports stadiums as Covid-19 rages. While the results in Olczak et al. (2020) suggest caution in re-opening outdoor stadiums, they were based on fan behaviour pre-Covid-19, without the subsequent adoption of social distancing, the wearing of face coverings, and the redesign of public spaces to remove potential pressure points where people may congregate. The results also come from an early stage in the spread of the virus, which may help to explain the different results found by a study of the mass outdoor gatherings during the summer Black Lives Matters (BLM) protests, which found no growth in Covid-19 cases or deaths in the weeks following these substantial 
relaxations of outdoor social distancing (Dave et al., 2020). There is a lot of heterogeneity in sports stadiums, as well as in how spectators normally experience a matchday. For example, BLM marchers are typically on the move, whereas sports crowds are largely static for up to two hours. These issues could be studied more closely, to understand whether there are restrictions short of a complete shutout that are manageable alongside Covid-19. The focus so far has been on how safe it is for the consumers of sport to return, with little attention given to the participants or staff involved with putting on these events and what employers can reasonably expect of them.

There are many unanswered questions about how demand for spectator sports will recover to pre-pandemic levels and trends. We expect there will be a flurry of research on this in the coming year. One important distinction for this research will be the issue of stated versus revealed preferences and demand. Most studies of stadium attendance demand in sports shy away from this distinction, as it is often unclear whether the reported attendances in part reflect tickets purchased well in advance (i.e., season tickets). This matters, as one study demonstrated when describing the behavioural response of German football fans to the 2015 Paris terrorist attacks, which would have otherwise been largely concealed when exploring such stated preferences (Frevel and Schreyer, 2020) - a lot of information can be revealed by studying the composition of stadium attendance demand, especially the no-shows for pre-purchased tickets. It will also be important to distinguish between casual and loyal sports fans in future demand research, with the latter group being more likely to purchase season tickets and the former group either purchasing them on or near the day of an event. In a different but comparable context, Becker and Rubinstein (2005) demonstrated that the demand responses for goods and services affected by terrorism in Israel were solely accounted for by the occasional users; frequent users (season ticket holders) did not change their demand for bus travel or coffee shops following related terrorist activity in the country. Sports could similarly be studied to understand what types of information about the risk of Covid-19 infection can predict significant demand responses for different types of consumers.

The studies of sports without the social pressure of a crowd have so far only scratched the surface. There are opportunities for deeper insights and more convincing descriptions of how the different participants and agents involved in contests are affected. For example, keeping the focus on football, the evidence so far is not entirely convincing that it is only referee bias that is affected by the lack of a crowd, rather than the different match outcomes being a result 
of changes to player behaviour also. Future studies could disentangle this by looking more carefully at the in-play match context when referees made their decisions. For example, do referees "level things up" less with no crowd? Are they less likely to award a penalty or red card to one team after awarding one to the other team? Alternatively, without a crowd, do referees add on less stoppage time at the end of the game per substitution made when the home team is losing? Association football was the first sport to return post-Covid-19 with large numbers of events. There are now also likely to be opportunities from studying the lack of social pressure on behaviour and outcomes in other sports, including individual sports played in very different environments to football (e.g., golf, snooker and darts). There are detailed studies waiting to be done on how the uses of technologies in sports have changed from their introduction prior to Covid-19 and over the period from March 2020. Simply, for example, has the time to a decision in football using the video assistant referee (VAR) been reduced by the absence of a crowd, and have on-field decisions been more correct during the lockdown period.

There remain uncertainties about the effects of 'long-Covid' on exercise and sporting performance (e.g., Dores and Cardim, 2020). In the first weeks of 2021, there have been a growing number of games postponed because of players contracting Covid-19. This will lead to a backlog of fixtures, which may disadvantage some more than others. Soon there will be enough data to analyse these effects within sports, drawing out insights for other markets and contexts. Some professional teams have had players out of action for many weeks with longCovid. The lasting effects on a team's performance could be studied, of what can be treated as a random draw on the amount of talent available.

Another area of importance is the distributional effects of Covid-19 on sports. As in so many other areas, those at the top of the pile have done well whilst those at the bottom have fared badly. In English football, for example, the incomes of the smaller non-Premier League clubs have been much more adversely affected, as their shares of television broadcast rights are much lower (Reade and Singleton, 2020b). This raises questions about the extent to which the bigger and richer sports firms should subsidise or bankroll the poorer and smaller firms because of Covid-19. Quite rightly, the richer firms point to the fact that in no other industry is it the case that some suppliers are forced to bankroll their failing competitors. However, this rhetoric ignores two important facts. First, a competitive sport fixture can only be produced if there are viable rivals to play against. Second, the big firms benefit from the small firms as 
nurseries for young talent coming through. This all relates to questions of competition, and specifically whether within sports having a concentration of success in a very few firms is sustainable. For example, one factor keeping the NFL and other North American sports alive and fascinating every season is the draft system: if a team finishes bottom of the rankings one season, it gets the first pick of new talent to potentially reverse its fortunes in the next or following seasons. If European football leagues go on being won from among a select few teams, then they could limit or destroy their own appeal. Covid-19, through its distributional effects, may very well exacerbate these problems. 


\section{References}

Ahammer, A., M. Halla, and M. Lackner. 2020. "Mass Gatherings Contributed to Early COVID-19 Spread: Evidence from US Sports." Covid Economics, CEPR. https://voxeu.org/article/mass-gatherings-contributed-early-covid-19-mortality

Bar-Eli, M., A. Krumer, and E. Morgulev. 2020. "Ask not what economics can do for sports - Ask what sports can do for economics." Journal of Behavioral and Experimental Economics, 89, 101597. https://doi.org/10.1016/j.socec.2020.101597

Benz, L. S., and M. J. Lopez. 2020. "Estimating the change in soccer's home advantage during the Covid-19 pandemic using bivariate Poisson regression." arXiv:2012.14949 https://arxiv.org/abs/2012.14949

Becker, G. S., and K. M. Murphy. 2000. Social Economics: Market Behavior in a Social Environment. Harvard University Press.

Becker, G. S., and Y. Rubinstein. 2011. "Fear and the Response to Terrorism: An Economic Analysis." CEP Discussion Papers dp1079, Centre for Economic Performance, LSE.

Bryson A., P. Dolton, J. J. Reade, D. Schreyer, and C. Singleton. 2021. "Causal effects of an absent crowd on performances and refereeing decisions during Covid-19." Economics Letters, 198, 109664. https://doi.org/10.1016/j.econlet.2020.109664

Cardazzi, A., B. R. Humphreys, J. E. Ruseski, B. Soebbing, and N. Watanabe. 2020. "Professional Sporting Events Increase Seasonal Influenza Mortality in US Cities." https://dx.doi.org/10.2139/ssrn.3628649

Croxson, K., and J. J. Reade. 2014. "Information and Efficiency: Goal Arrival in Soccer Betting." The Economic Journal, 124(575): 62-91. https://doi.org/10.1111/ecoj.12033

Dave, D. M., A. I. Friedson, K. Matsuzawa, J. J. Sabia, and S. Safford. 2020. "Black Lives Matter Protests, Social Distancing, and COVID-19.” NBER Working Paper No. 27408. https://www.nber.org/papers/w27408

Dores H., and N. Cardim. 2020. "Return to play after COVID-19: a sport cardiologist's view." British Journal of Sports Medicine, 54: 1132-1133

Deutscher C., D. Winkelmann, and M Ötting. 2020. "Bookmakers' mispricing of the disappeared home advantage in the German Bundesliga after the COVID-19 break." https://arxiv.org/abs/2008.05417v2

Dohmen, T., and J. Sauermann. 2016. "Referee Bias." Journal of Economic Surveys, 30(4): 679-695. https://doi.org/10.1111/joes.12106 
Endrich, M., and T. Gesche. 2020. "Home-Bias in Referee Decisions: Evidence from 'Ghost Matches' During the COVID-19 Pandemic.” Economics Letters, 197, 109621. https://doi.org/10.1016/j.econlet.2020.109621

Fischer, K., and J. Haucap. 2020. "Betting Market Efficiency in the Presence of Unfamiliar Shocks: The Case of Ghost Games During the COVID-19 Pandemic.” CESifo Working Paper No. 8526. https://ssrn.com/abstract=3692914

Frevel, N., and D. Schreyer. 2020. "Behavioral responses to terrorist attacks: empirical evidence from professional football." Applied Economics Letters, 27(3), 244-247. https://doi.org/10.1080/13504851.2019.1613490

Humphreys, B., G. A. Wagner, J. C. Whitehead, and P. Wicker. 2020. "Beyond Ghost Games: The value of avoiding COVID-19 with masking and social distancing in U.S. professional sports." https://www.youtube.com/watch?v=zND-c6LMSV4

Levitt, S. D. 2004. "Why are gambling markets organised so differently from financial markets?" The Economic Journal, 114(495): 223-246. https://doi.org/10.1111/j.1468$\underline{0297.2004 .00207 . x}$

Meier, P. F., R. Flepp, and E. P. Franck. 2020. “Are Sports Betting Markets Semistrong Efficient? Evidence from the COVID-19 Pandemic." UZH Business Working Paper No. 387. http://dx.doi.org/10.2139/ssrn.3676515

Olczak, M., J. Reade, and M. Yeo. 2020. "Mass Outdoor Events and the Spread of an Airborne Virus: English Football and Covid-19." Covid Economics, CEPR. https://voxeu.org/article/spread-covid-19-and-attending-football-matches-england

Pettersson-Lidbom, P., and M. Priks. 2010. "Behavior under social pressure: Empty Italian stadiums and referee bias." Economics Letters, 108(2): 212-214. https://doi.org/10.1016/j.econlet.2010.04.023

Reade, J. J., and C. Singleton. 2020a. "Demand for public events in the COVID-19 pandemic: a case study of European football." European Sport Management Quarterly, Forthcoming. https://doi.org/10.1080/16184742.2020.1841261

Reade, J. J., and C. Singleton. 2020b. "European football after COVID-19.” In "A new world post COVID-19: lessons for business, the finance industry and policy makers," M. Billio and S. Varotto (Ed.), Ca' Foscari University Press.

Reade, J. J., D. Schreyer, and C. Singleton. 2020a. "Stadium attendance demand during the COVID-19 crisis: early empirical evidence from Belarus." Applied Economics Letters, Forthcoming. https://doi.org/10.1080/13504851.2020.1830933 
Reade, J. J., D. Schreyer, and C. Singleton. 2020b. "Eliminating supportive crowds reduces referee bias." Economics Discussion Papers em-dp2020-25, Department of Economics, Reading University. https://dx.doi.org/10.2139/ssrn.3743972

Scoppa, V. 2021. "Social Pressure in the Stadiums: Do Agents Change Behavior without Crowd Support?” Journal of Economic Psychology, 82, 102344. https://doi.org/10.1016/j.joep.2020.102344

Snowberg, E., and J. Wolfers. 2010. "Explaining the Favorite-Long Shot Bias: Is it RiskLove or Misperceptions?” Journal of Political Economy, 118(4): 723-746. https://doi.org/10.1086/655844

Stoecker, C., N. J. Sanders, and A. Barreca. 2016. "Success Is something to sneeze at: Influenza mortality in cities that participate in the Super Bowl." American Journal of Health Economics, 2(1): 125-143. https://doi.org/10.1162/AJHE_a_00036

Thaler, R., and W. T. Ziemba. 1988. "Anomalies: Parimutuel Betting Markets: Racetracks and Lotteries." Journal of Economic Perspectives, 2(2): 161-74.

https://doi.org/10.1257/jep.2.2.161 
Figure 1 Summary of regression results of football match activity on mortality in the first half of 2020 in England (Olczak et al., 2020)
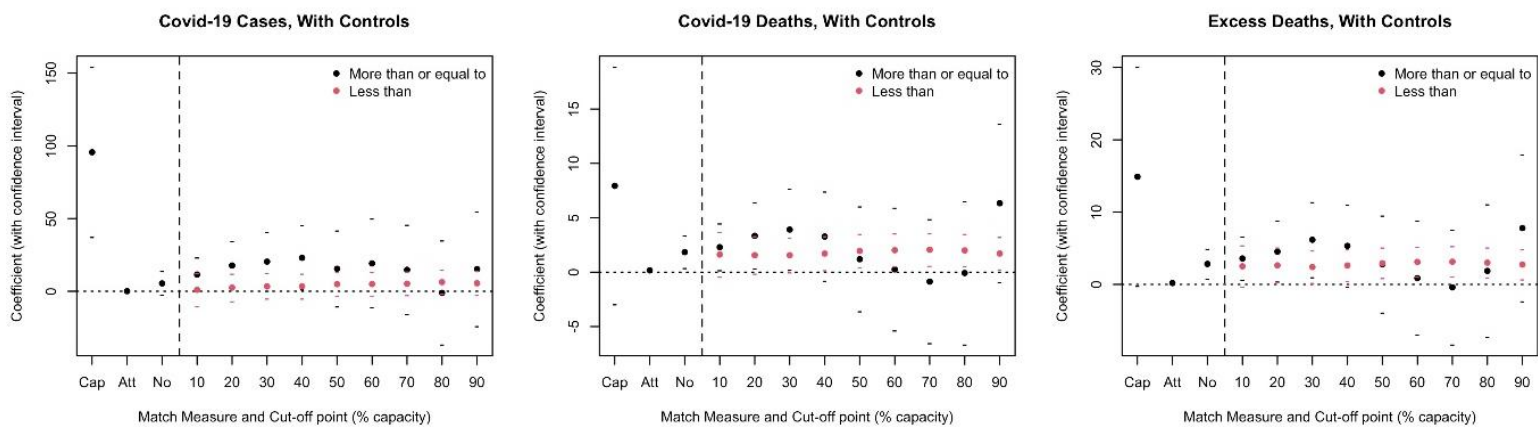

Notes: Each column of plots relates to a measure of mortality (Covid-19 cases, Covid-19 deaths, and excess deaths), the top row is without any control variables, and the bottom row adds control variables. Solid dots are regression coefficients on the footballing measure, and circles are the upper and lower confidence intervals (90\% significance level).

Figure 2 Home advantage in Professional Football, 1880 - 2020.

Outcomes by Half Year, Since 1869

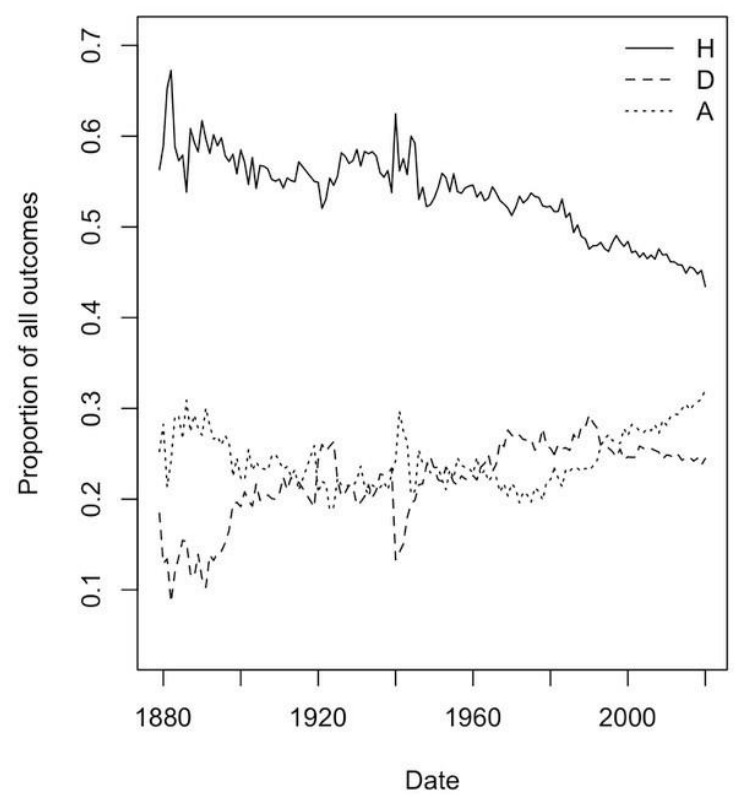

Outcomes by Month, Since 2016

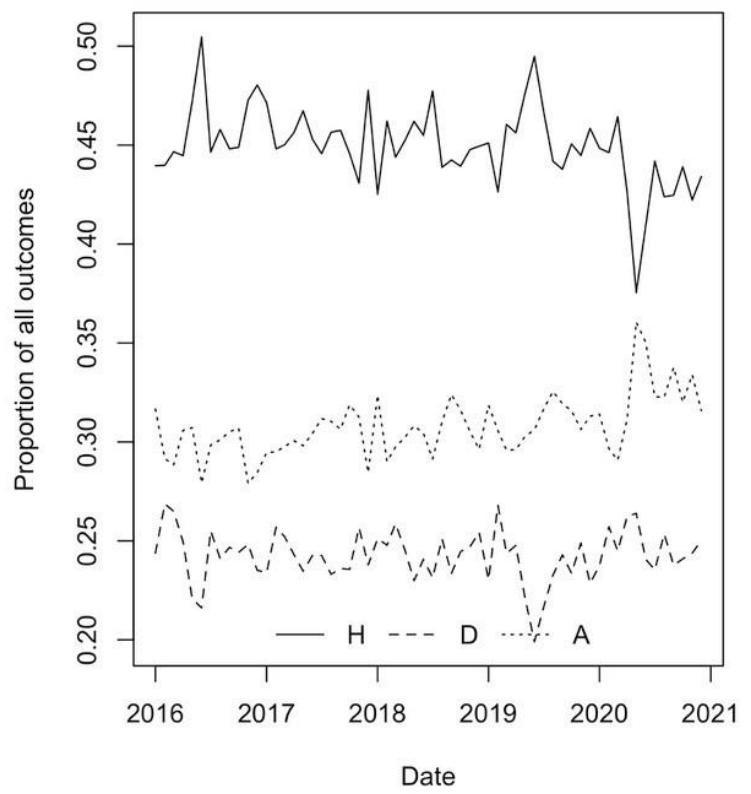

Notes: author calculations using data from worldfootballdata.net (accessed 12/1/2021) on the entire history of results in professional association football matches up to the end of 2020. $\{\mathrm{H}, \mathrm{D}, \mathrm{A}\}=\{$ Home win, draw, away win\} 
Figure 3 Average match differences between home and away team outcomes within professional football leagues, 2019/20 season, before and after shutdown. (Bryson et al., 2021)

\section{A. Goal Difference}

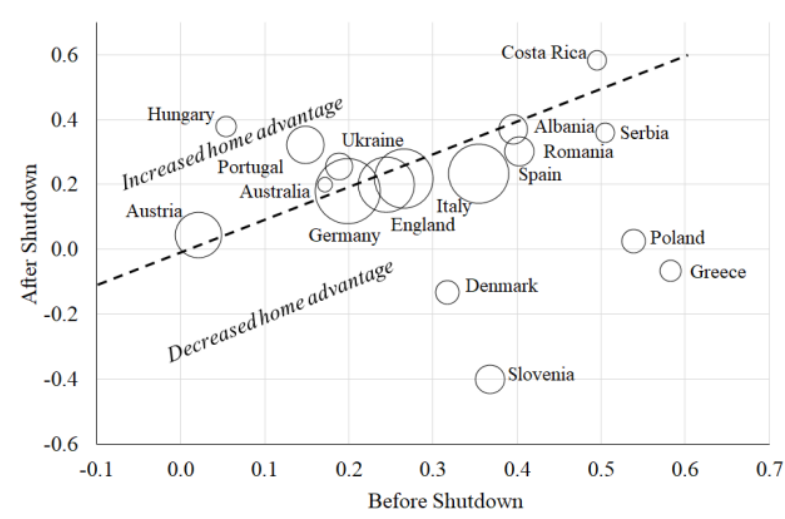

B. Yellow Card Difference

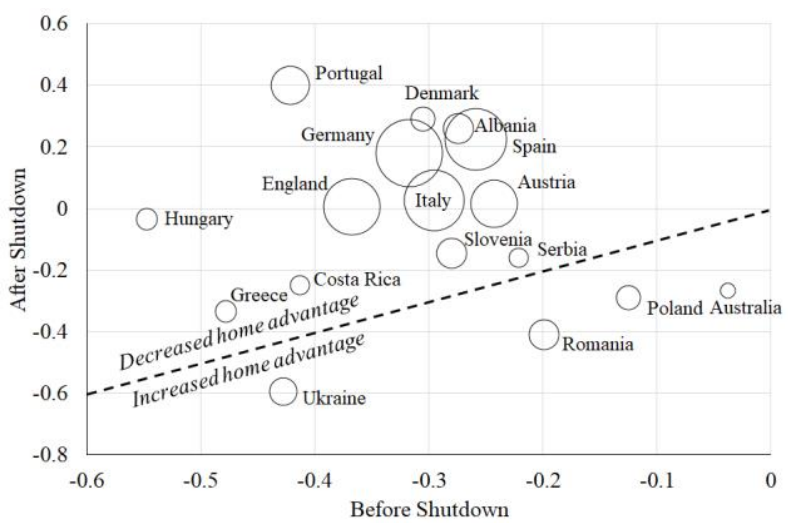

Notes: author calculations using data from worldfootballdata.net, accessed 3/8/2020. Averages of Home minus Away outcomes over all matches in the sample periods. Dashed line is $y=x$. Bubbles are proportional in area to the number of matches in the dataset in each country after 1 April 2020. Leagues represented: Australia, ALeague; Albania, Superliga; Austria, Bundesliga and Bundesliga 2; Costa Rica, Primera Divisíon; Denmark, Super-liga; England, Premier League and Championship; Germany, Bundesliga, 2. Bundesliga and 3. Liga; Greece, Super League; Hungary, OTP Bank Liga; Italy, Serie A and Serie B; Poland, Ekstraklasa; Portugal, Primeira Liga; Romania, Liga 1; Serbia, SuperLiga; Slovenia, PrvaLiga; Spain, La Liga and Segunda Divisíon; Ukraine, Premier League. 